\title{
Research on the Application of big data in Engineering Education in Colleges and Universities
}

\author{
Fengxiang Jiang* \\ *Business Department, Xi'an Peihua University, Xi'an Shannxi,China 710125
}

Keywords: Big Data; Engineering Education; Colleges and Universities

\begin{abstract}
In the era of big data, educational decision-making, educational policy, educational concept, educational scientific research paradigm and cultivation of school core competence are all impacted, and the importance of educational big data is becoming more and more important. The big data is applied in the engineering education of colleges and universities. It is of great significance to construct the modern engineering education through big data. This paper first studies big data and its characteristics, then analyzes the characteristics of educational big data, and then analyzes the current situation and trend of big data application in engineering education in colleges and universities, and finally attempts to explore the application of big data in engineering education in colleges and universities.
\end{abstract}

With the development of the Internet, big data is applied in engineering education in colleges and universities. Big data is applied to the construction of adaptive learning system. Big data will become a powerful assistant to teachers teaching and help teachers more. We should give full play to our role and promote students learning better.

\section{The Definition and Characteristic of Big Data}

Big Data refers to a large set of data collected from many sources in multiple forms, often with real - time performance. In the case of enterprise sales, these data may be available from social networks, e - commerce sites, customer visit records, and many other sources. These data are not normal data sets for the company undefined s customer relationship management database. Big data has a wide range of data sources, including traditional relational databases and semi-structured data such as XML, as well as unstructured data in video, audio, text and other forms. The main problem to be solved in data extraction and integration is to collect all kinds of fragmented data, to clean the data, to ensure the data quality, and to update the data pattern according to the evolution of time, and to determine the data entity and its relationship. Finally, the data is stored in a uniform format to be provided to the upper layer for data analysis.

\section{The Definition and Characteristic of Big Data of Education}

In terms of the composition of educational big data, online learning data bear the brunt. It can be said that the widespread concern of educational big data is closely related to the prevalence of online teaching and learning. In Steinberger Peer with big data: the Future of Learning and Education, the first case of an big data education application comes from online learning. With the increasing popularity of online teaching, the massive data recorded by the learning management system and various mobile devices have become an important source of teaching analysis in the 
process of teaching and learning. These data include the behavior data of the learning process, the evaluation data of the learning results, and the data of the social network relationship formed by the learning. By the expansion of these data, educational big data also contains all kinds of student personal information data, teaching management data and so on. Therefore, educational big data comes from the main body and process of education and teaching. According to different levels of subjects and contents of educational activities, educational big data can be divided into four levels and six types. Four levels include individual, school, region and country; six types include basic data, teaching data, scientific research data, management data, service data and public opinion data. Among them, the basic data include the basic information data of learners represented by demography, the teaching data include the process, content and result data involved in the teaching process. Scientific research data include data obtained from various educational experiments and scientific research projects, management data include data recorded in various educational management systems, such as student status data, archival data and various statistical data, etc. Service data include data recorded in various service systems related to education and teaching, such as various teacher-student services, library and archival services, etc. Public opinion data include education-related data in various public media, such as, all kinds of educational news data, Weibo and other social network systems in education-related data.

\section{The Application of Big data in Higher Engineering Education: Current Situation and Trend}

It is well known that large data are characterized by huge volume, a wide variety, and mostly unconventional, unstructured (unstructured) and high-speed data information. It can be quickly analyzed and provided analysis results to decision-makers in the "almost" real time situation. The purpose of using large data is to provide advice or to solve practical questions. Rather than creating new theories or exploring the reasons for interpreting data, it can be used to identify and predict patterns so as to improve the economic efficiency of enterprises. More than 10 years ago, big data was first developed in large enterprises and large companies seeking efficiency. The reasons for the rise of big data can be attributed to two factors: (1) advances in data collection technologies, such as the use of various sensors, data digitization, and collection of sound, images, coordinates, speed and data from the Internet and social networks. The technical ability of various data inside; (2) development of computer hardware. These improvements have improved the functions of data processing, analysis and visualization.

The combination of these two factors effectively provides data and results for the decision-makers. Although enterprises and organizations have accepted the development and wide application of large data, the application in higher engineering education is still relatively slow. The colleges and universities have not given priority to improving efficiency for a long time. The areas of higher education do not exist in the necessary factors such as the technology, funds and expertise needed in the early stage of the development of large data. In many companies, people are not the research objects of large data use, but products and workflow. People are considered the object of customer service, and groups or students are regarded as the products and research subjects of higher education. Because human behavior is more complex than products and work processes, the large data framework is implemented in higher education. There will be additional difficulties.

In higher engineering education, a large number of factors promote the use of big data, including the growing accountability needs of government officials and policymakers, board of directors, teachers and parents, and parents. They require more information on financial management, teaching effects and curriculum design, retention rates and graduation rates, and the availability and use of student services. The reduction of state funding has led to the need for senior 
managers in public institutions to pay more attention to resource allocation and efficiency through strategic planning, assessment and key performance indicators (KPI).As a source of income and prestige for many institutions, the increase in the number of students from colleges and universities, enrollment and graduation is becoming more and more important. The goal of the institution is to recruit more and better students, to increase the number of students, to make up the existing gap and to ensure that students graduate within six years. The implementation of strategic planning and the improvement of the reputation of the school And ranking factors are related to the next budget.

The first surge in the application of large data in higher education is largely caused by the above factors. Large data methods are applied to real-time, visual dynamic information, interaction, and KPI real-time demonstration, which meet the needs of decision-makers. In theory, institutions have many types of data, which can be placed in large numbers. It is used in the framework, including traditional structured data such as data, as well as unstructured data such as logging in to Blackboard, entering libraries and participating in campus activities. At present, most applications of large data are structured in Colleges and universities, and universities do not have the ability to make full use of large data. Construct dashboards to create a dashboard to guide functional areas. Examples of this use can be seen on the agency website, the introduction of the conference, and the sponsorship of the AIR annual forum. About ten years ago, Tableau had only a small share on the aviation forum, only a few organizations used its products. Now Tableau is a higher education. A leader in the virtualization of market data, organizations find that if they do not install Tableau, SAS Virtual analytics or IBM Cognos, they will be left behind.

The process of creating the dashboard begins with most organizations that buy off the - shelf software. At present, a popular model is the IT - led development of the dashboard of each functional area in the IT and IR fields. Any functional department can participate in this process. The data management committee is responsible for ensuring the accuracy of the data and the definition of the data. At the same time, the committee can provide software training in the form of group guidance or self-study. In most cases, consulting companies do not need to do this. The content of the dashboard covers many areas of operation, including budget, finance, research, enrollment, registration, financial assistance, and course assessment and student assessment data. In most institutions, development often comes from functional departments with more close data relations with the IR office, such as student enrollment, registration and registration, and human resources, rather than research, financial and budgetary related departments. Usually early developed dashboards have more powerful functions and wider coverage. This is because of it often attracts more attention, and the IR department can provide better data support.

For these effects, large data plays a greater role in learning analysis and participation in analysis than in general institutional analysis. Large data is quite effective in the first two aspects, because it has successfully combined multiple offices and colleges to share data and provides special information to senior managers, professors, staff and students. Other analyses and results are used to improve the efficiency of the teachers and the results of the students. However, it has a limited impact on the institutional analysis, because it can only answer some basic or direct questions. However, the first climax of higher education in the United States is compared to the most easily picked fruit in the big data age. Interactive dashboards, data virtualization and KPI cannot replace depth analysis and prediction. Even organization senior managers have 7/24 access to data and have a full understanding of the organization. Quantification ally determine where a $\$ 5$ million increase should be allocated to the largest strategic impact on the agency. If their goal is to raise the graduation rate by $5 \%$, the senior managers facing many real-time interactive dashboards still cannot figure out what measures should be taken and how many budgets to be made to achieve 
this. How long will it take and how it will affect the ranking. To answer these questions, a complex model is needed, and the data of several functional departments need to be carefully merged, analyzed and predicted. In other words, large data have not been fully used in institutional analysis.

\section{The Application of Big Data in Engineering Education in Colleges and Universities}

Through the international typical technology, products and services, from three aspects of adaptive teaching, education law discovery and precision management support, the international application of big educational data which has great influence is analyzed in order to provide reference for the application of large data to the development of Engineering Education in China.

\subsection{Adaptive Teaching Support}

Adaptable teaching and learning are the optimal state of teaching. The content, method and process of adaptive teaching can be customized according to the situation of the learners, so that every learner is likely to obtain the best development for them. The realization of adaptive teaching needs to be based on the individual characteristics and learning conditions of the learners. Face analysis. Big data provides the possibility of tracking and integrating these data and personalized support for students. The most common adaptive teaching system comes from the field of online learning. In various learning management systems and online learning platforms, the learners undefined learning process can be fully recorded. The records of the learning process, combined with the character data such as demography and learning style, can clearly characterize the learning path and learning of the learners. On the basis of effective recording of learning process and comprehensive evaluation of learning conditions, diagnosis and recommendation are carried out and targeted teaching is carried out. Adaptive learning support has almost become the "marking" of online learning, with varying degrees of adaptability in every commercial online learning platform. Content recommendation is a major form of adaptability. However, a truly effective adaptive teaching system requires the integration of three systems, namely, the knowledge system, the behavioral system and the characteristic system. The knowledge system is used to describe the knowledge system; the learning, practice, and feedback processes are recorded by the behavioral system; and the individual characteristics and learning characteristics of the students are analyzed by the characteristic system.

Under the support of large data technology, teachers can monitor students learning according to their own needs and make automated or semi-automated evaluation of students through their own standards. Under the support of data, teachers can combine their own teaching experience to diagnose and intervene students. Under the training of teachers, large numbers of students are trained. Tools will provide stronger support for teachers teaching. Big data tools will be the best help for teachers, not competitors. The support of teaching and learning is the two aspects of the application of large data in adaptive learning. Based on data, the students learning state can be fully recorded, the learning system can be pushed to the customized content, and the teachers can carry out more targeted teaching. The data are changing the teaching process on the line and under the line.

\subsection{The Discovery of the Law of Education}

Education research is a complex systematic study. For a long time, the small sample size and case study have played an important role in the exploration of the law of education. The introduction of large educational data has greatly expanded the perspective of the exploration of the 
law of education. Under the drive of large data, educational research will have different trends. Through mining and analyzing large data of education, researchers can quantify the learning process, describe the learning state, find the influencing factors, find the intervention strategies, and reveal the educational rules from a deeper level. On the basis of quantitative data, data collection and sharing are carried out by technical means, and group collaboration is organized by the researchers to carry out a large number of studies that can be standardized and with comparative significance.

\subsection{The Real Education Rules Can Be Found More Easily}

Big data research needs a lot of data collection; data collection needs a large number of researchers, and also needs effective organizational mechanisms. The data store (Data Shop) of the Pittsburgh Science of Learning Center (the University of Pittsburgh Learning Science Center) is the learning science data supported by the National Natural Science Foundation of the United States. After more than 10 years of construction, it has become the world largest learning data sharing community. Data store with two major functions: data storage and data analysis. On the one hand, it provides secure data storage and sharing tools for global learning researchers; on the other hand, it provides data analysis tools and invoking interfaces. Data stores in data stores are divided into public data and private data, and researchers can choose whether their data should be published as required. Data store data, including teaching software application data, online course data, Intelligent Tutoring Systems, virtual laboratory data, collaborative learning On the basis of data collection and sharing functions, the data store provides a rich data analysis function, supports exploratory statistical analysis and data mining.

\section{References:}

[1] Hongtao Sun, Qinghai Zheng. The Core Technology, Application Status and Development Trend of Big Data of Educational [J]. Journal of distance Education, 2016, 34(5): 41-49.

[2] Mingqi Chen, Jianhui Li, Xiaohuan Zheng, et al. Development Trend and Suggestion of Scientific Dig Data [J]. China Education Informatization, 201621: 5-9.

[3] Guanhao Wang. Development Trend and Countermeasures of Information Economy in Big Data Era [J]. Heilongjiang Science, 2016,7 23: 80-81.

[4] Fengya Wang. Analyzing the Development Trend and Countermeasures of Information Economy in Big Data Era [J]. Human Resources Management, 2017: 9: 11-12.

[5]Wu Yu-lin. A brief Analysis of the Application of Big Data in the Field of Education in China [J]. Computer Research in Fujian, 2018.

\section{Acknowledgements}

Fund Project: Education Science Planning Project of Shaanxi Province in 2017: Innovation International Talents System of Shaanxi University Supporting the Construction of Belt and Road Initiative (SGH17H456)

\section{Profile of the Author:}

Fengxiang Jiang (1983.07-), female, Institution of Business, Xi'an Peihua University, Associate Professor, research interests: Regional Economics, Human Resource Management and Entrepreneurship Education 